\title{
A Notação Musical para Cistre e os Tratados de Geminiani (1760) e Silva Leite (1796)
}

\author{
Mario André Vlaxio Lopes, Luciano Hercílio Alves Souto \\ Universidade do Estado do Amazonas | Brasil
}

\begin{abstract}
Resumo: $O$ artigo trata de duas formas de escrita musical - a tablatura e a notação mensural - utilizadas no ensino e na difusão da prática musical da guitarra inglesa. Partindo da perspectiva dos tratados The Art of Playing Guitar or Cittra (1760) de Francesco Geminiani e Estudo de Guitarra (1796) de Antonio da Silva Leite, realiza um estudo musicológico em fontes primárias e secundárias relacionadas ao instrumento e às notaçôes verificadas nos respectivos tratados, discutindo suas aplicabilidades na prática musical dos intérpretes de hoje. Neste sentido, busca conhecer o papel da notação em relação à época por meio da contextualização histórica dos tratados e dos instrumentos em questão, envolvendo aspectos prático-instrumentais e didáticopedagógicos vinculados ao instrumento. As informações coletadas e apresentadas contribuem para a compreensão das ideias expressas pelos autores, elucidando aspectos relevantes do ponto de vista teórico e prático-interpretativo do instrumento.
\end{abstract}

Palavras-chave: Notação musical, Tablatura, Guitarra inglesa, Francesco Geminiani, Antonio da Silva Leite.

\begin{abstract}
The article approaches two forms of musical writing - tablature and mensural notation - used in teaching and in the dissemination of the musical practice of the English guitar. From the perspective of the treatises The Art of Playing Guitar or Cittra (1760) by Francesco Geminiani and Estudo de Guitarra (1796) by Antonio da Silva Leite, it conducts a musicological study on primary and secondary sources related to the instrument and the notations verified in the respective treatises, discussing their applicabilities in the musical practice of today's interpreters. In this sense, it seeks to understand the role of notation in relation to the time throughout the historical context of the treaties and instruments in question, involving practicalinstrumental and didactic-pedagogical aspects linked to the instrument. The information collected and presented contributes to the understanding of the ideas expressed by the authors, elucidating relevant aspects from the theoretical and practical-interpretative point of view of the instrument.
\end{abstract}

Keywords: Musical notation, Tablature, English Guitar, Francesco Geminiani, Antonio da Silva Leite. 
prensa desenvolvida por Johannes Gutenberg durante o século XV contribuiu
significativamente para a expansão e difusão do registro impresso através de um método
organizado e rápido, possibilitando a um número maior de indivíduos o acesso a diversos saberes e não a apenas um grupo exclusivo (SOUZA, 2012; MARIANO, 2013). No caso da música, a difusão do conhecimento se apoia em determinadas formas de escrita que podem servir tanto ao aprendizado formal e institucionalizado quanto de suporte à oralidade e ao aprendizado não formal, como, por exemplo, as tablaturas para cordas dedilhadas do século XVI ao século XVIII, que serviram a essas duas finalidades, conforme observa Nogueira (2016):

O aprendizado da notação musical foi historicamente associado às camadas privilegiadas da sociedade. Assim o descrevem os textos amplamente conhecidos das áreas de História da Música e Musicologia. Temos por certo, contudo, tratarem de um excerto da produção musical, dado que a prática popular excede, em grande número, a das elites. $\mathrm{O}$ levantamento histórico das fontes de documentação musical de que se serviram tratou, exclusivamente, da música escrita em notação convencional e, em larga escala, de manuscritos e publicaçôes até fins do século XIX. A partir da institucionalização do aprendizado musical com o advento dos conservatórios, surgiu a demanda por publicaçôes de textos didáticos que uniformizassem o conhecimento musical.

De outro lado, as cordas dedilhadas e, particularmente, as guitarras ou violas, serviram à produção musical de todas as camadas da sociedade, desde suas origens árabes, até a difusão pela Europa e por suas colônias. Seu aprendizado se deu por meio não formal, seja pela tradição oral ou não letrada, seja por outras formas de letramento (possivelmente a razão de sua enorme popularidade), desconsideradas naquelas publicaçôes didáticas, à exceção de pequenas citaçôes ao alaúde e às vihuelas. A institucionalização mesma do ensino desses instrumentos ocorreu muito tardiamente em relação aos instrumentos de orquestra e ao piano (NOGUEIRA, 2016, p. 119).

Para Grout e Palisca (2001, p. 97, grifo do autor), "uma obra composta podia ser ensinada e transmitida oralmente”, porém, “podia sofrer alterações neste processo de transmissão. Mas a invenção da notação musical tornou possível escrever a música de uma forma definitiva, que podia ser aprendida a partir do manuscrito”. Durante os diversos períodos da história da música ocidental, a notação esteve sempre em transformação, atendendo, ainda que com limitações, as necessidades expressivas e ou comunicativas de cada época. Sobre a análise da notação musical gregoriana empreendida por Lorenzo Mammi (1998-1999), Nogueira (2008; 2016) observa que o autor vincula a transformação da notação musical à mudança do pensamento filosófico sobre as artes, contrapondo os códigos notacionais da escrita musical gregoriana e seus respectivos elementos significativos aos valores estéticos que regiam as normas musicais de então, revelando o seu 
significado à época em que foram escritos.

Sobre a escrita gregoriana e sua transcrição moderna, Mammi (1998-1999) escreve:

Se, por exemplo, acrescentarmos a uma partitura de Palestrina as linhas de compasso, ausentes no original, as durações das notas não mudam, mas o intérprete moderno poderá medi-las com um sistema a ele mais familiar.

No entanto, a linha de compasso não é apenas um instrumento neutro de medida: ela estrutura o texto musical em células métricas fixas, células que eram absolutamente estranhas ao pensamento musical renascentista. Palestrina concebia as frases musicais como linhas contínuas e indivisíveis, e não como um conjunto de células. O intérprete moderno, portanto, se não quiser violentar o texto, deverá esquecer os compassos para tentar reconstruir a fluência da curva melódica - num certo sentido, deverá trabalhar contra a transcrição, extraindo dela, mentalmente, a escrita original. (MAMMI, 19981999, p. 22).

Como se pode observar, o desenvolvimento da música ocidental ao longo do tempo conduziu a notação musical por diversas transformaçốes e adaptações, muitas vezes redefinindo seus limites e sua estrutura conforme as necessidades expressivas e os valores estético-filosóficos de cada época, até se estabelecer da forma convencional como a conhecemos. Sobre tais transformaçóes, Nogueira (2016) escreve:

A notação moderna da música, cujos fundamentos remontam ao período dito renascentista, teve como herança as transformaçôes advindas do pensamento artísticomusical, suas demandas sonoras, acústicas, expressivas, estruturais e formais. Para além de transformações dos códigos de notação, o sistema incorporou signos de representação dos mais variados fenômenos da expressão musical, chegando ao que hoje referimos como notação musical moderna. Diferente das notaçôes mais antigas já encontradas, que se baseavam na escrita verbal grega e incluíam elementos de sua enunciação, a notação incorporada pelo aprendizado musical moderno e, em particular, por aquele institucionalizado, é específica, abrange elementos que se relacionam com seu significado de forma simbólica (representação convencional de seu objeto) e, por essa razão, possui múltiplos aspectos de aprendizado que produziram tratados teóricos da escritura e da enunciação musical. Assim, o sistema de ensino musical foi estruturado a partir de cada um desses aspectos advindos da complexidade de escrita e de representação gráfica da música e, a partir dela, surgiram novas disciplinas interdependentes do sistema de notação. Em paralelo, as cordas dedilhadas produziram um sistema de notação que, por sua representação gráfica das cordas (ou ordens de cordas) do instrumento, constituiu-se em um modelo iconográfico de notação que perdura por séculos, desde os primórdios da imprensa. Suas variantes compreendem os signos indiciários das alturas segundo sua posição no braço do instrumento e são representadas por números (tablaturas italiana e espanhola) ou por letras do alfabeto (tablatura francesa). Seguem as convençôes espaciais de altura da notação convencional (agudo na parte superior) as tablaturas francesa e espanhola. Já a tablatura italiana, a de maior classificação iconográfica, reproduz as alturas conforme a representação visual do braço do instrumento: grave em cima e agudo nas linhas inferiores. (NOGUEIRA, 2016, p. 123-124). 
Conforme se pode observar, a notação em si não é um simples procedimento atemporal e universal que possa permanecer da mesma forma ao longo dos séculos. Essa observação é corroborada por Harnoncourt (1988, p. 34) em seu Discurso dos Sons, no qual escreve: "é um erro fatídico crer - como acontece em grande escala — que as figuras de notação, as indicações de caráter e tempo, e as dinâmicas têm ainda hoje o mesmo significado de antigamente”. Essa mesma ideia é apontada por Fischer (2009, p. 14) em sua obra intitulada História da Escrita, ao pontuar que "a escrita tem sido, é e será inúmeras coisas distintas para inúmeros povos disitintos [sic] em incontáveis épocas diferentes”. A semelhança na grafia não assegura a mesma significação. Um conjunto de fatores como mudanças estilísticas musicais, aliadas às ideias dos compositores e dos executantes, altera também em maior ou menor grau o significado dos diversos códigos da escrita musical existentes.

Considerando as notaçôes para guitarra inglesa utilizadas pelos dois autores (Geminiani e Silva Leite) - um de origem italiana e radicado na Inglaterra, e o outro de origem Portuguesa —, veremos como as possibilidades de notação existentes lhes propiciou atingirem objetivos comuns por caminhos diversos, ou seja, qual seja, a criação de material impresso para a instrução e o desenvolvimento prático da guitarra.

\section{A guitarra inglesa}

Após a ausência de um instrumento de cordas dedilhadas de apelo popular durante a primeira metade do século XVIII, a Grã-Bretanha testemunhou na segunda metade do século, o surgimento de um novo instrumento: a guitarra inglesa ${ }^{1}$, instrumento de seis ordens (quatro duplas nas primeiras cordas e duas simples nas seguintes). Essa breve ausência mencionada é apontada por Tyler e Sparks (2007, p. 206, tradução nossa): “durante a primeira metade do século XVIII, a guitarra de cinco ordens e com cordas de tripa perdeu progressivamente o status e a popularidade de que gozava na Grã-Bretanha [...] no século XVII, quando era um dos instrumentos favoritos da

\footnotetext{
${ }^{1}$ Não se trata propriamente de uma guitarra, mas de uma espécie de cistre. (TYLER; SPARKS, 2007, p. 206).
} 
corte do rei Charles II" . Os autores afirmam ainda que essa guitarra "tinha praticamente desaparecido por completo da consciência popular inglesa em meados do século XVIII”3.

A boa impressão que a nova guitarra causou na Grã-Bretanha do início da segunda metade do século XVIII permitiu sua crescente popularidade tanto no círculo das famílias nobres, no apreço por parte das jovens senhoras, quanto na utilização por artistas amadores (COGGIN, 1987, p. 206; TYLER; SPARKS, 2007, p. 207). Esse instrumento (Figura 1) faz parte de uma ampla família de instrumentos de cordas dedilhadas encordoados com material metálico, desenvolvidas como alternativa aos encordoamentos de tripa animal, relativamente frágeis e, muitas vezes, de difícil afinação. A nova guitarra ofereceu algumas vantagens, como o seu formato mais cômodo para segurá-la, mecanismo de afinação mais fácil de manuseio, afinações mais simples, e sua desenvoltura em apresentações ao ar livre. Essas particularidades gradualmente popularizam o instrumento que passou a ocupar "um papel importante dentro de várias configuraçôes musicais e fornecendo sua própria voz distinta para vários estilos musicais”‘ (POULOPOULOS, 2011, p. 50, tradução nossa).

FIGURA 1 - a. Desenho de uma guitarra inglesa presente no tratado Estudo de Guitarra de Silva Leite; b) Fotografia de uma guitarra inglesa, mod. Longman e Broderip, 1785.

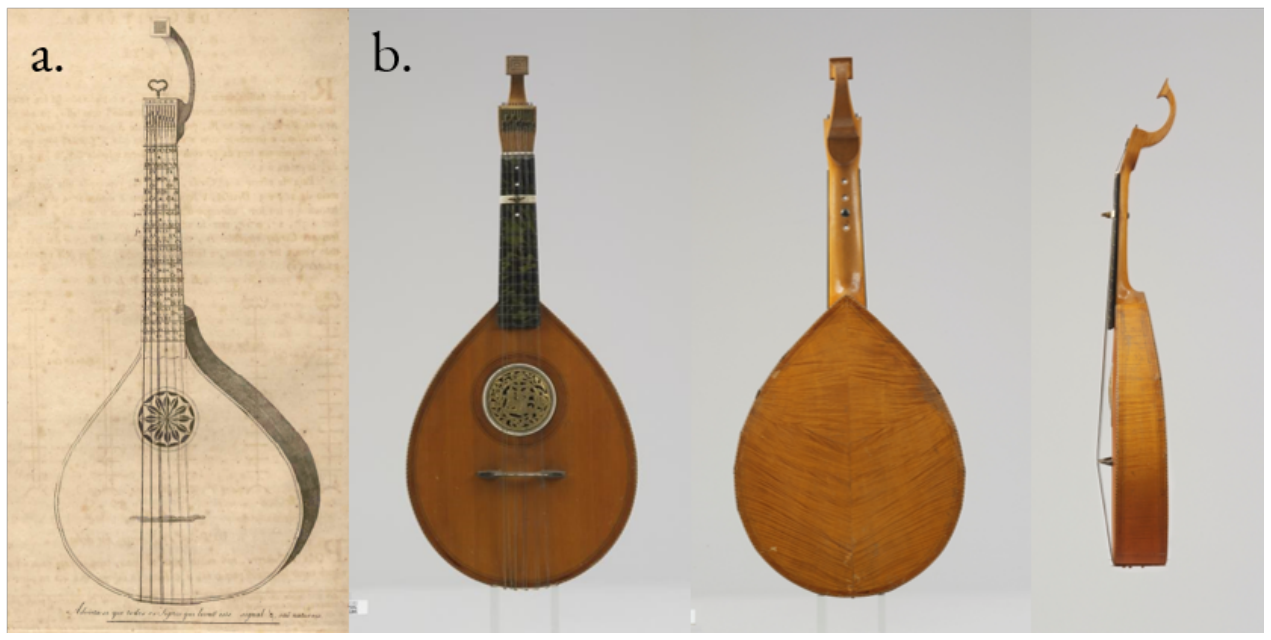

Fonte: LEITE (1796, p. 30); Longman e Broderip (1785 apud MIMO, 201?)

\footnotetext{
2 "during the first half of the eighteenth century, the five-course, gut-strung guitar steadily lost the status and the popularity it had enjoyed in Britain [...] during the seventeenth century, when it had been a favourite instrument at the court of King Charles II".

3 "it had virtually disappeared altogether from the popular English consciousness by the middle of the eighteenth century".

4 "an important role within various musical settings and providing their own, distinctive voice to several musical styles".
} 
O instrumento, no final do século XVIII, na Grã-Bretanha, era popularmente conhecido como guittar. "No entanto, o instrumento tem sido amplamente conhecido como English guittar [guitarra inglesa] desde o início do século XIX, quando se tornou necessário distingui-lo das então emergentes guitarras 'Espanholas' ou 'Francesas'”' (POULOPOULOS, 2011, p. 46, tradução nossa). A popularidade da guitarra inglesa foi acompanhada por inúmeras coletâneas musicais e diversos tratados escritos para o instrumento. Desta forma, os dois autores tomados como referência neste artigo foram escolhidos por terem contribuído significativamente para o desenvolvimento prático do instrumento: o primeiro, Francesco Geminiani (1687-1762), participou de sua difusão desde seu aparecimento na Grã-Bretanha, enquanto o segundo, Antonio da Silva Leite (17591833), participou na continuidade da popularização. Ambos nos legaram dois importantes tratados dedicados à prática da guitarra inglesa. Geminiani, compositor e tratadista, era natural da Itália, mas se radicou na Inglaterra ainda por volta da primeira metade do século XVIII ${ }^{6}$. Silva Leite, compositor, tratadista e mestre de capela da Sé do Porto, era natural de Portugal. Embora a temporalidade e a espacialidade entre esses autores sejam contrastantes, ambos contribuíram para a popularização da guitarra inglesa. Geminiani lança seu tratado voltado à guitarra inglesa em 1760, denominado de "The art of playing guitar or cittra". Três décadas depois, em 1796, Silva Leite lança o seu tratado nominado "Estudo da Guitarra". Ambos se propóem a um objetivo em comum, o de ensino e difusão da prática do instrumento. Geminiani, tendo percebido que a guitarra voltou a gozar de interesse e popularidade na corte setecentista inglesa - principalmente pelo timbre peculiar que o instrumento oferecia e pelo fácil manuseio de execução do mesmo - , aproveitou para "compor algumas liçôes adaptadas à extensão e ao estilo desse instrumento" (Geminiani, 1760, p. 1, tradução nossa), e empenhou-se, igualmente, “em aprimorá-las, adicionando mais harmonia e modulação à maneira usual de se executá-las"». O instrumento também foi muito popular em Portugal no século XVIII. A entrada da guitarra inglesa em Portugal e sua acolhida pela sociedade mercantil aconteceram na cidade do Porto, pela barra do Douro, através do comércio de vinho e

\footnotetext{
5 "Nevertheless, the instrument has been widely known as 'English guittar' since the beginning of the 19th century, when it became necessary to distinguish it from the then emerging 'Spanish' or 'French' guitars".

${ }^{6}$ Mais precisamente, em 1714 (NEVES, 2017, p. 16; PÁSCOA; SBAFFI, 2020, p. 2).

7 "to Compose some Lessons adapted to the compass and stile of that Instrument".

8 "to improve it by adding more Harmony and Modulation to the usual manner of performing on it".
} 
cortiça. Por conseguinte, os primeiros tocadores de guitarra chegaram a Portugal, onde ricos comerciantes britânicos firmaram estadia na cidade do Porto, comprando casas e terras e criando respeitáveis associações empresariais (BESSA, 2008; POULOPOULOS, 2011; MELO, 2014). Silva Leite aproveitou-se dessa popularidade do instrumento e escreveu também para "o suave, e harmonico instrumento da Guitarra, taó applaudida neste tempo, por todos que sabem deleitar-se com a doçura da harmonia” (LEITE, 1796, p. 3).

\section{The Art of Playing the Guitar or Cittra (1760), de Francesco Geminiani e Estudo de Guitarra (1796), de Antonio da Silva Leite}

O tratado de Geminiani ${ }^{9}$ destinado à guitarra inglesa ou cistre, apresenta-se em dois momentos: no primeiro, o autor oferece um breve prefácio contendo informaçóes sobre a quem se destina a obra, sobre a retomada da popularidade da guitarra durante o século XVIII (principalmente durante a segunda metade do século XVIII) e fornece explicaçôes práticas para o entendimento da notação usada e seu manejo ao instrumento. No segundo, Geminiani apresenta onze sonatas de três a cinco movimentos contrastantes como exemplos musicais em diversas tonalidades para o bom desenvolvimento na guitarra. As peças vêm acompanhadas de uma linha de violino e uma outra linha cifrada de baixo contínuo e, como sugere o compositor, devem ser tocadas por um violoncelo e/ou um cravo.

O tratado de Silva Leite ${ }^{10}$ divide-se em duas grandes partes distintas e mais uma parte voltada para a prática do instrumento com algumas peças. $\mathrm{Na}$ primeira parte apresenta os assuntos distribuídos em vinte e oito tópicos. Aborda conhecimentos básicos e teóricos da música como o nome das notas, o pentagrama, as claves, os acidentes musicais, os tempos e os compassos, as figuras musicais e seus respectivos valores, contemplando sinais de expressão, andamentos, tonalidade e culminando nas regras pertinentes para se fazer um bom acompanhamento apenas pelo baixo contínuo. $\mathrm{Na}$ segunda parte, voltada à guitarra inglesa, os assuntos encontram-se distribuídos em vinte e seis tópicos. Há, primeiramente, uma atenção especial ao instrumento como o da invenção e

\footnotetext{
${ }^{9}$ Sobre a vida e obras de Gemiani, ver Neves (2017).

${ }^{10}$ Sobre a vida e obras de Silva Leite, ver Bessa (2008).
} 
serventia, da construção e das qualidades necessárias a uma boa afinação, das cordas (tipo, quantidade, ordenamento e como "ferir" as mesmas) e do procedimento de afinação. Segue com tópicos sobre uma boa postura para segurar a guitarra e a posição dos dedos no instrumento, formas de execução, disposição das notas (escalas diatônicas) e intervalos no instrumento que, segundo o autor, servem "para se tocar qualquer Peça com flexibilidade, bom modo, e gosto; e finalmente com uma viva, e tocante expressão, a que chamam Estilo; se atenderá muito aos Apojos de Capricho, que os mais das vezes, e quase sempre se devem supor, e entender, ainda que não expressos” (LEITE, 1796, p. 35). A parte prática do tratado, ao final, conta com 40 peças de autoria do próprio Silva Leite. Esta coleção apresenta pequenas peças musicais como Minuetos, Marchas, Contradanças, Allegros e outros, todas compostas para duas guitarras, e na tonalidade de Dó maior. A estruturação das peças é binária, com sinal de repetição ao fim de cada seção. Silva Leite apresenta ainda outro dueto para guitarra, Tocata em Fá maior, de autoria de Francisco Gerardo, totalizando 41 peças.

\section{Notação musical}

Os dois tratados mencionados apresentam, cada um, suas particularidades em relação à notação musical: Geminiani utiliza a tablatura espanhola (Figura 2) e Silva Leite emprega a notação mensural ou convencional (Figura 3). Harnoncourt (1988, p. 35, grifo do autor) discute dois princípios básicos para a utilização de ambas as notações escolhidas pelos autores: sobre a tablatura, afirma que "é a execução que é notada, sendo a notação, ao mesmo tempo, uma indicação da maneira de se tocar"; para a notação convencional, afirma que "é a obra, a composição em si, que é notada, não sendo sua execução indicada por esta notação”.

FIGURA 2 - Trecho retirado da peça Giga, compassos 11-15, ilustrando a tablatura espanhola.

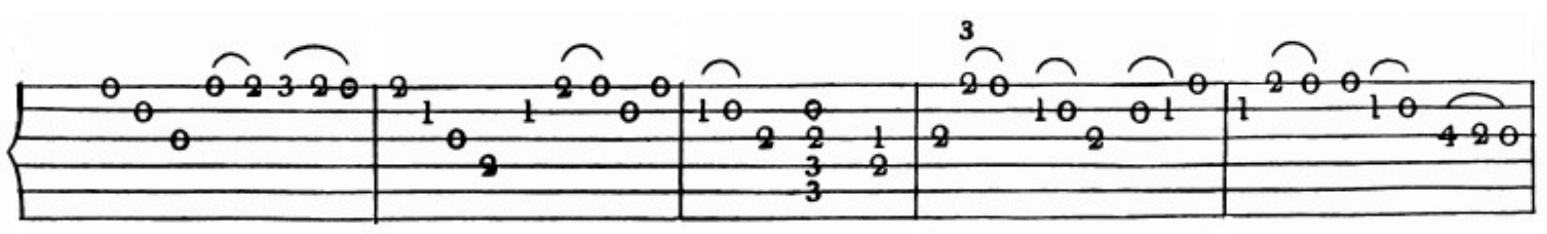

Fonte: GEMINIANI (1760, p. 6) 
FIGURA 3 - Trecho retirado da peça Minueto, compassos 1-8, ilustrando a notação mensural ou convencional.

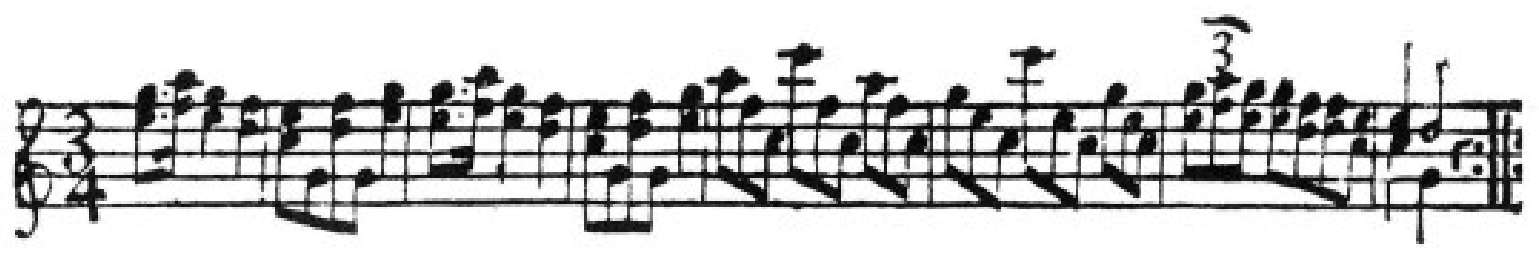

Fonte: LEITE (1796, p. IV)

A notação musical é estruturada por um conjunto de códigos cuja convenção determina o modo como se relacionam entre si, constituindo a estrutura e o sentido musical. A disposição dos códigos na escrita musical traduz o som para signos visuais segundo uma hierarquia de valores sóciohistórico-culturalmente determinados, sobre os quais Mammi (1998-1999, p. 21) escreve: "Sem dúvida, a escrita, tanto musical quanto verbal, funciona sempre como uma espécie de filtro: os aspectos do evento sonoro que ela inclui passam a ser considerados significativos, os que exclui se tornam contingentes e irrelevantes.” Nessa perspectiva o autor utiliza uma classificação semiótica icônica, indiciária, simbólica empregada inicialmente por Treitler (1980) para classificar diferentes tipos de notação e, posteriormente, foi empregada por Nogueira (2008) e Souto (2010; 2015) para tratar especificamente das tablaturas para cordas dedilhadas. Tal classificação estabelece distinções capazes de identificar as diferenças entre as tablaturas e a notação mensural moderna a partir dos aspectos do evento sonoro que são selecionados e daqueles que são excluídos por cada uma dessas notações a partir de suas características prevalentemente icônicas, indiciárias ou simbólicas. Desta forma, a tablatura utilizada por Geminiani, em virtude de suas características icônicas e indiciárias, se refere aos gestos necessários para a obtenção do som desejado, enquanto a notação mensural empregada por Silva Leite é composta basicamente por códigos simbólicos. Sobre tais classificações, Mammi (1998-1999) explica:

As harmonizações de música popular, nas quais os acordes são representados por letras e/ou números, são simbólicas. Por outro lado, as grades que reproduzem esquematicamente o braço do violão ou do alaúde, nos manuais modernos como nas antigas tablaturas, carregam marcas que sugerem a posição dos dedos para cada som a ser obtido, e são, portanto, índices imperativos. A notação em pauta, por outro lado, possui um estatuto ambíguo. Ainda que se destine à execução, ela não é indiciária, porque a maioria de seus signos se refere diretamente a sons, e apenas indiretamente aos gestos necessários para produzi-los. É simbólica, em parte, porque nela a relação entre signo e significado é arbitrária por muitos aspectos. A duração proporcional dos sons, por 
exemplo, é indicada pela forma das notas, que são totalmente convencionais. Os signos dinâmicos também são símbolos, na medida em que utilizam letras ou outras cifras para significar variações de volume ou de ataque. O parâmetro das alturas, ao contrário, não é representado por um vocabulário de signos específicos, mas pela posição dos signos (notas) no espaço. A altura é indicada pela posição da nota, não por sua forma, e uma sequência de notas ao longo da pauta forma um desenho que consideramos intuitivamente como a reprodução de uma linha musical. Entre as notas tomadas singularmente e a linha que elas formam no conjunto há uma diferença substancial: aquelas são símbolos dos sons, essa é um ícone da forma melódica. Os contornos que a escrita traça, no entanto, não existem senão a partir dela, porque os sons, em si, não produzem linhas. A rigor, a passagem de um som a outro não é um movimento, mas uma transformação.

A notação, portanto, não se limita a reproduzir movimentos no espaço sonoro: ela cria a intuição desses espaços e desses movimentos. $\mathrm{O}$ caráter icônico da escrita musical moderna se baseia em duas analogias preliminares: o correr do tempo é representado no papel por um movimento da esquerda para a direita; a oposição grave /agudo é realizada graficamente pela oposição baixo/alto. Essas correspondências são arbitrárias e, portanto, simbólicas. Todavia, não são signos, mas apenas convenções que permitem a criação de um campo de representação. (MAMMI, 1998-1999, p. 24-25).

No caso da escrita de Geminiani, voltada aos gestos necessários à obtenção do som, portanto à execução instrumental, apresenta uma textura homofônica e, às vezes, polifônica, dispondo de elementos significativos que se resumem a números, linhas e barras verticais. O primeiro elemento, indicado por números, correspondem aos pontos ou casas, distribuídos no braço (espelho, escala) do instrumento onde são posicionados os dedos para obter determinado som. O zero (0) significa que a corda em questão é tocada solta, sem a intervenção de algum dedo sobre a escala; o 1, 2, $3 . . .12$ significa uma posição estabelecida para posicionamento de algum dedo. O segundo elemento, indicado por linhas, são uma representação das cordas do instrumento e onde são colocados os pontos (números). São dispostas no sentido horizontal; a direção cima/baixo é entendido como agudo/grave; a primeira corda na escrita é a de cima, a mais aguda do instrumento. O terceiro elemento, indicado por barras, é uma representação das barras de compasso, dispostas no sentido vertical sobre as cordas (linhas horizontais).

Geminiani utiliza ainda quatro elementos significativos de execução. O primeiro elemento, números dispostos sobre os pontos (números) indicando uma digitação adequada para se tocar. $\mathrm{O}$ segundo elemento, linhas oblíquas dispostas sobre vários pontos (números) indicando que um acorde deve ser executado em um gesto rápido de arpejo. $\mathrm{O}$ terceiro elemento, traço curvado disposto sobre dois ou mais números (pontos), indicando uma articulação. Executa-se uma única vez a corda onde está o primeiro dedo posicionado e os demais dedos, na passagem de uns para 
outros, produzirão o restante dos sons. O último elemento, o ritmo, curiosamente, não vem diretamente na notação para guitarra, devendo o executante observar o tempo e o valor das notas da linha do violino, que também se faz presente nas composiçốes juntamente com a linha do violoncelo. A Figura 4 traz uma exemplificação desses elementos.

FIGURA 4 - Trecho retirado da peça Allegro moderato, compassos 1-9, Violino, Guitarra e Violoncelo, ilustração da escrita de Geminiani.

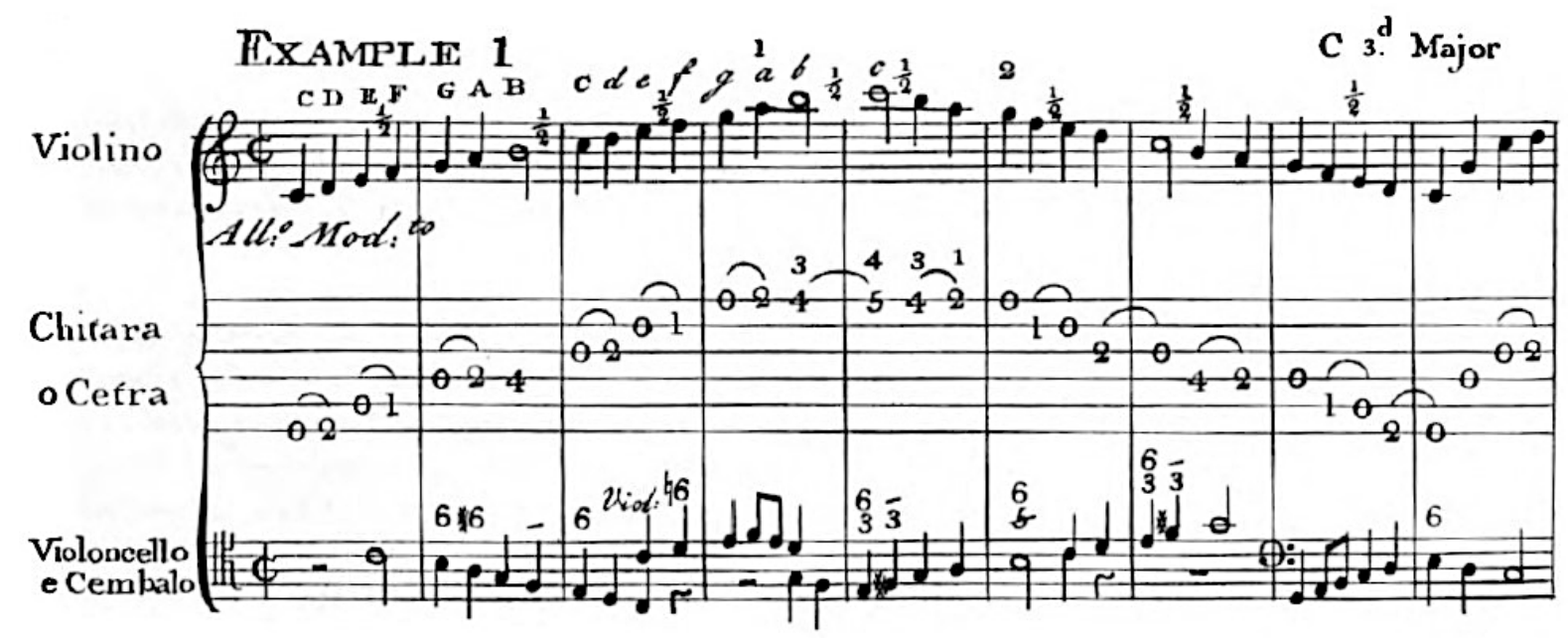

Fonte: GEMINIANI (1760, p. 2)

A notação descrita acima, utilizada por Geminiani, corresponde à tablatura em estilo espanhol (NOGUEIRA, 2008; 2016; SOUTO, 2020). Existem ainda pelo menos mais três tipos: francesa, italiana e alemã, empregadas por outros instrumentos de cordas dedilhadas, como guitarras e alaúdes da época, todas apresentando elementos significativos como números, linhas, letras capitais entre outros códigos. Como observado por Nogueira (2016), a tablatura francesa é semelhante à tablatura espanhola, diferenciando-se apenas na utilização de letras capitais do alfabeto, em vez de números como indicação das casas no braço do instrumento. A tablatura italiana é semelhante às anteriores, diferenciando-se apenas no sentido de leitura das cordas - a direção cima/baixo é entendida como grave/agudo; a primeira corda na escrita é a de baixo, a mais aguda do instrumento. A tablatura alemã é diferente das demais por não apresentar linhas horizontais indicando as cordas, mas sim códigos (letras e números) que indicam ao mesmo tempo a corda e a casa que o músico deve pressionar para obter uma nota específica. Em todas essas tablaturas, à exceção da tablatura empregada por Geminiani, o ritmo ou duração das notas é representado por 
códigos convencionais da notação vocal. O ritmo pode vir escrito de forma integral, ou abreviado quando o valor de duração de uma nota for igual a anterior. A Figura 5 traz uma exemplificação desses modelos de tablaturas.

FIGURA 5 - a. Branle de Village, Jean-Baptiste Besard, comp. 11-12, tablatura francesa; b. Canários, Gaspar Sanz, comp. 1-2, tablatura italiana; c. Nach willen dein, Hans Gerle, comp. 1-2, tablatura alemã.

a.

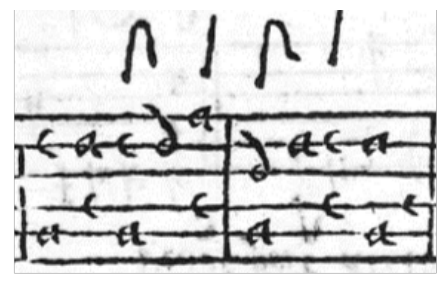

b.

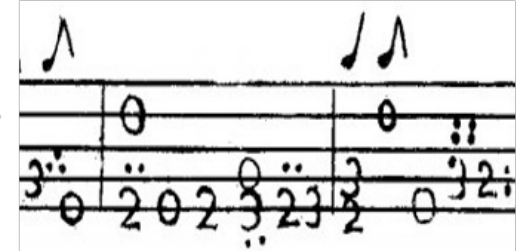

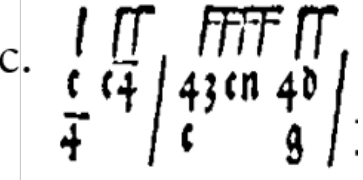

Fonte: $\operatorname{BESARD}$ (1617, p. 28); SANZ (1697, p. 8); GERLE (1532, p. 80)

Além do tratado de Geminiani, alguns outros trabalhos didáticos anteriores foram publicados na Grã-Bretanha com a notação em tablatura, como por exemplo: The cittarn schoole (1597), de Antony Halborne; New citharen lessons (1609), de Thomas Robinson; e A booke of new lessons for the cithern and gittern (1652), de John Playford. Essas obras são indícios do vínculo de Geminiani com a tradição das cordas dedilhadas da época, uma vez que o uso da notação convencional vinha sendo empregado como escrita padrão para guitarra inglesa. A tablatura teve grande importância na difusão dos instrumentos de cordas dedilhadas, mas "também determinou quase que o total desaparecimento dos mesmos no final do séc. XVIII na Europa” (SOUTO, 2010, p. 25). Ainda, segundo o autor, "tal escrita era totalmente específica e exigiria do compositor grande conhecimento do instrumento para o qual viesse a compor. Por esta razão, as tablaturas foram sendo gradativamente substituídas pela notação musical convencional”.

A notação convencional utilizada por Silva Leite passou por diversos processos de transformação desde o século IX e surgiu como emprego de escrita para a música vocal utilizando, a priori, sinais conhecidos como neumas (BENT et al., 2001, p. 22). Ainda segundo os autores, "Tal notação neumática é claramente de grande importância histórica, pois está no início do 
desenvolvimento que levou às formas de notação em uso hoje"11 (tradução nossa). Atualmente, uma das características dessa notação convencional é a valorização da altura da nota e sua duração. Apresenta ainda a estrutura da música, a obra em si, não considerando a execução, característica da tablatura. Embora mais antiga do que a tablatura, somente por volta da segunda metade do século XVIII é que a notação convencional passou a ser adotada como escrita para instrumentos de cordas dedilhadas. Nesta, os elementos significativos de ritmo e compasso continuam presentes, porém existem ainda outros elementos, todos eles dispostos sobre e/ou em volta de um conjunto de linhas, a pauta (pentagrama).

A escrita de Silva Leite, voltada para a obra, apresenta uma estrutura polifônica e homofônica, dispondo de elementos significativos como linhas, barras, números, claves e outros elementos (figura 6). O primeiro elemento, indicado por cinco linhas dispostas no sentido horizontal, em que se escrevem as notas musicais, tanto na linha quanto nos espaços intermediários; e quando necessário, são adicionadas linhas suplementares superiores ou inferiores. O segundo elemento, indicado por barras, é o mesmo da tablatura à época. O terceiro elemento, indicado por números, refere-se à fórmula de compasso que indica a espécie e a quantidade de figuras que cabem no compasso. O quarto elemento, as claves, são sinais colocados no início da pauta referenciando uma determinada nota, por exemplo: a clave de Sol indica o lugar da nota Sol na segunda linha, sendo as demais notas partindo dessa referência. Existem ainda outros elementos que indicam digitação, articulação, andamento, dinâmica, expressão e outros.

FIGURA 6 - Peça Pastorella, primeira guitarra, ilustração da escrita de Silva Leite.

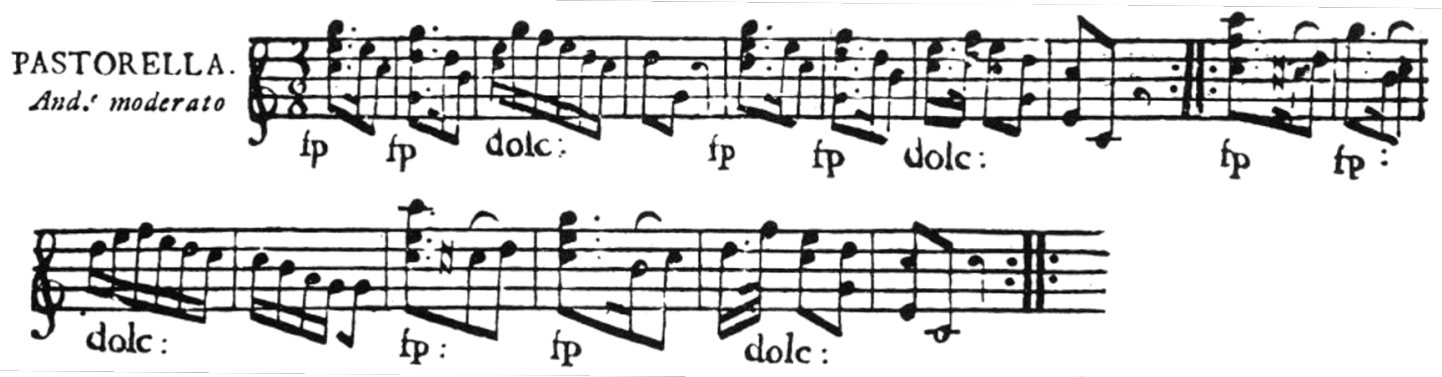

Fonte: LEITE (1796, p. XVI)

\footnotetext{
11 "such neumatic notation is clearly of great historical importance, for it stands at the beginning of the development that led to the notational forms in use today”.
} 
Além do tratado de Silva Leite, alguns outros trabalhos didáticos e coleções de peças musicais anteriores ao seu foram publicados na Grã-Bretanha com a escrita em notação convencional, como por exemplo: Instructions for the guitar (1758), de Robert Bremner; A pocket book for the guitar (1775), de Longman, Lukey e Broderip; e Art of playing the guittar (1781), de Edward Light. Essas obras são indicativos de que Silva Leite seguiu a escrita padrão adotada para os instrumentos de cordas dedilhadas, como a guitarra inglesa, ainda na segunda metade do século XVIII.

Comparando os tratados de ambos os autores ante à exposição das notaçóes, importa mencionar que a guitarra inglesa esteve auxiliada por materiais relevantes para o seu desenvolvimento no meio sócio-cultural de sua época. Tanto a tablatura quanto a notação convencional possuem elementos característicos que atendem a determinadas necessidades específicas. Devemos levar em consideração que “as regras dos tratados antigos só começam a tornar-se interessantes para a prática a partir do momento em que as compreendemos - ou, pelo menos, quando elas fazem algum sentido para nós” (HARNONCOURT, 1988, p. 39).

\section{Considerações finais}

Após a apreciação comparativa dos procedimentos de escrita musical e das metodologias de ensino instrumental utilizadas pelos tratadistas Francesco Geminiani e Antonio da Silva Leite, verificou-se que a notação para guitarra inglesa seguiu por dois caminhos, porém, ambos levando ao mesmo propósito: a instrução e o ensino da execução do instrumento. A tablatura, que apresenta uma estrutura de execução dos gestos necessários para tocar o instrumento, mostra-se a mais direta para o fazer musical na medida em que se refere diretamente aos gestos necessários à produção do som no instrumento, constituindo por este motivo um importante dispositivo de acesso à linguagem instrumental da época. Na medida em que traduz exatamente os movimentos prescritos pelo compositor no que se refere ao comportamento tanto da mão direita quanto da mão esquerda no braço e nas cordas do instrumento, expressa diretamente o pensamento do compositor em relação ao trato com o instrumento. Desta forma, a estrutura musical se revela como fenômeno sonoro resultante da realização dos gestos ao instrumento, prescritos pela tablatura. A notação convencional, por sua vez, apresenta aspectos relacionados com a estrutura musical, tais como 
tonalidade, polifonia, textura, conteúdo e forma, exigindo que o executante detenha algum conhecimento prévio da leitura desse tipo de escrita, bem como sobre onde e como posicionar os dedos no diapasão, correspondentes às notas escritas na partitura para o respectivo instrumento, conteúdos esses contemplados por Silva Leite em seu tratado. Portanto, ambos os tratados se tornam complementares na medida em que abordam conteúdos específicos, porém, diferenciados pelo tipo de notação empregada, condicionando tais conteúdos às necessidades de leitura musical desses dois sistemas de notação musical, (tablatura e partitura). É certo que o iniciante, quando deparado com esses tipos de escrita, esteja sob supervisão ou tutela de um professor. Nos dias atuais é comum o uso de edições em que as duas notações venham juntas, complementando-se uma à outra.

Desta forma, concluímos que os tratados datados da segunda metade do século XVIII apresentam condições reais para o músico moderno que tenha interesse em aprender a tocar a guitarra inglesa, e seu repertório, tanto no instrumento original quanto em outros instrumentos de cordas dedilhadas, seja do passado ou do presente, recuperando uma prática instrumental e um repertório muitas vezes esquecido pela historiografia das cordas dedilhadas e pelo público atual. Portanto, os tratados examinados constituem uma importante fonte de informaçóes sobre a prática musical e o repertório da guitarra inglesa, sobretudo na Inglaterra e em Portugal na segunda metade do século XVIII e primeira metade do século XIX.

\section{REFERENCIAS}

BENT, I. et al. Notation. Grove Music Online, 2001. Disponível em: <https://www.oxfordmusiconline.com/grovemusic/view/10.1093/gmo/9781561592630.001.000 1/omo-9781561592630-e-0000020114 >. Acesso em: 21 out. 2020.

BESARD, Jean-Baptiste. Novus Partus. Augsburgo: Davidem Francum, 1617.

BESSA, Rui Manuel Pereira da Silva. António da Silva Leite: criatividade e "moda" na música romântica portuense. 2008. Tese (Doutorado em Ciências Musicais) - Faculdade de Letras, Universidade de Coimbra, 2008. Disponível em: <https://estudogeral.sib.uc.pt/handle/ $\underline{10316 / 9900>}$. Acesso em: 9 set. 2018.

COGGIN, Philip. This easy and agreable Instrument: a history of the English guittar. Early Music, v. 15, n. 2, p. 205-220, maio 1987. Disponível em: <https://doi.org/10.1093/earlyj/XV.2.205>. Acesso em: 17 set. 2020. 
FISCHER, Steven R. História da escrita. Tradução Mirna Pinsky. São Paulo, Editora UNESP, 2009.

GEMINIANI, F. The art of playing the guitar or cittra. Edinburgh: Robert Bremner, 1760.

GERLE, Hanz. Musica Teusch. Nuremberga: Hieronymus Formschneider, 1532.

GROUT, D; PALISCA, C. História da música ocidental. Tradução Ana Luísa Faria. 2a ed. Lisboa, Gradiva, 2001.

HARNONCOURT, Nikolaus. O discurso dos sons: caminho para uma nova compreensão musical. Tradução Marcelo Fagerlande. Rio de Janeiro: Jorge Zahar Editor, 1988.

LEITE, Antonio da Silva. Estudo de guitarra em que se expóem o meio mais fácil para aprender a tocar este instrumento. Porto: Officina Typografica de Antonio Alvarez Ribeiro, 1796. Disponível

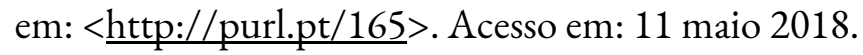

MAMMI, Lorenzo. A notação gregoriana: gênese e significado. Revista Música, São Paulo, v. 9 e 10, p. 21-50, 1998-1999. Disponível em: <https://doi.org/10.11606/rm.v10i0.61749>. Acesso em: 10 out. 2020.

MARIANO, Sara M. B. A estruturação de notaçôes na iconografia, música, dança e escrita como base para a reflexão acerca dos códigos escriturais no teatro. 2013. Dissertação (Mestrado em Artes) Instituto de Artes, Universidade de Brasília, 2013. Disponível em: < https://repositorio.unb.br/handle/10482/14282 >. Acesso em: 10 out. 2020.

MELO, Arménio Coelho de. O Percurso da Guitarra Portuguesa através dos seus métodos e práticas. 2014. Dissertação (Mestrado em Ciências Muscais) - Faculdade de Ciências Sociais e Humanas, Universidade Nova Lisboa, 2014. Disponível em: < http://hdl.handle.net/10362/19098 >. Acesso em: 12 ago. 2018.

MIMO. Musical Instrument Museums Online. English guitar. Nurembergue: Museu Nacional, 201? Disponível em: <https://mimo-international.com/MIMO/doc/IFD/OAI_GNM 899916>. Acesso em: 11 mar. 2021.

NEVES, Marcus. Francesco Geminiani (1687-1762): comentários e tradução da obra teórica completa. 2017. Dissertação (Mestrado em Música) - Escola de Comunicações e Artes, Universidade de São Paulo, 2017. Disponível em: < https://doi.org/10.11606/D.27.2017.tde27092017-101128>. Acesso em: 08 set. 2020.

NOGUEIRA, Gisela. A viola con anima: uma construção simbólica. 2008. Tese (Doutorado em Interfaces Sociais da Comunicação) - Escola de Comunicação e Artes, Universidade de São Paulo, 2008. Disponível em: < https://teses.usp.br/teses/disponiveis/27/27154/tde-15052009140811/pt-br.php>. Acesso em: 19 set. 2020.

A viola e suas metalinguagens: notação do gesto no aprendizado não formal. Revista Tulha, Ribeirão Preto, v. 2, n. 1, p. 119-143, jan.-jun. 2016.

PÁSCOA, M; SBAFFI, E. Pietro Giorgio Avondano. Dicionário Biográfico Caravelas Núcleo de Estudos da História da Música Luso-Brasileira, 2020. 
POULOPOULOS, Panagiotis. The guitar in the British Isles, 1750-1810. 2011. Tese (Doutorado em Filosofia) - School of Arts, Culture and Environment, The University of Edinburgh, 2011. Disponível em: $<$ https://www.era.lib.ed.ac.uk/handle/1842/5776 $>$. Acesso em: 2 jul. 2018.

SANZ, Gaspar. Instruccion de musica sobre la guitarra española, y metodo de sus primeros rudimentos, hasta tañerla con destreza. Zaragoza: por los herederos de Diego Dormer, 1697. (Tomo I).

SOUTO, Luciano H. A. Transcrição Musical: um estudo critico do repertório para instrumentos de cordas dedilhadas. 2010. Dissertação (Mestrado em Música) - Instituto de Artes, Universidade Estadual Paulista Júlio De Mesquita Filho, 2010. Disponível em: < http://hdl.handle.net/11449/93750>. Acesso em: 10 out. 2020.

Inter-relaçôes entre Performance e Musicologia Histórica: perspectivas para a interpretação musical. 2015. Tese (Doutorado em Música) - Instituto de Artes, Universidade Estadual Paulista Júlio de Mesquisa Filho, (UNESP), 2020. Disponível em: < http://hdl.handle.net/11449/123954 >. Acesso em: 10 out. 2020.

. A guitarra inglesa e a viola de arame no século XVIII: aproximações notacionais, técnico-idiomáticas e transcrição de excertos do Exemplo musical no II, extraído do The Art of Playing the Guitar or Cittra (1760) de Francesco Geminiani. Música e Interfaces, v. 1, p. 43-59, 2020. Caroline Caregnato e Márcio Páscoa (organizadores). Disponível: http://repositorioinstitucional.uea.edu.br/bitstream/riuea/3227/1/M\%c3\%basica\%20e\%20interfa ces.pdf. Acesso em: 20 jan. 2021.

SOUZA, Maria de Nazaré V. A Evolução da Notação Musical do Ocidente na História do Livro até à Invenção da Imprensa. 2012. Dissertação (Mestrado em Ciências Documentais) - Artes e Letras, Universidade da Beira Interior, 2012. Disponível em: <http://hdl.handle.net/10400.6/3407>. Acesso em: 12 out. 2020.

TREITLER, Léo. History and Archetypes. In: Perspectives of New Music, [s.l.] v. 35. n. 1, p. 115127. Winter, 1997. Disponível em: < http://www.jstor.org/pss/833681> . Acesso em: 20 jan. 2021.

TYLER, J; SPARKS. P. The guitar and its music: from the renaissance to the classical era. New York: Oxford University Press, 2007.

\section{SOBRE OS AUTORES}

Mario André Vlaxio Lopes é mestrando no Programa de Pós-graduação em Letras e Artes da Universidade do Estado do Amazonas (PPGLA/UEA), e bacharel em Música (2012) pela Escola Superior de Artes e Turismo (ESAT/UEA). Foi professor substituto (2018) no Curso de Música da Faculdade de Artes da Universidade Federal do Amazonas (FAARTES/UFAM). É bolsista da FAPEAM. ORCID: https://orcid.org/0000-0002-4741-9795. E-mail: mario.vlaxio@outlook.com. 
LOPES, Mario André Vlaxio; SOUTO, Luciano Hercílio Alves. A Notação Musical para Cistre e os Tratados de Geminiani (1760) e Silva Leite (1796). Revista Vórtex, Curitiba, v.9, n.1, p. 1-18, 2021.

Luciano Hercílio Alves Souto é pós-doutor em Música, doutor em Performance (2015), mestre em Práticas Interpretativas (2010) e bacharel em violão (2006) pelo Instituto de Artes UNESP - SP. Leciona nos Cursos de Graduação em Música e Pós-graduação em Letras e Artes da Universidade do Estado do Amazonas (UEA) onde participa do Laboratório de Musicologia e História Cultural e da Orquestra Barroca do Amazonas, como instrumentista (guitarra barroca e viola de arame). ORCID: https://orcid.org/0000-0001-5218-4479. E-mail: lhsouto@yahoo.com.br. 